\title{
Probable Creutzfeldt-Jakob disease-a case report at Suez Canal University Hospital, Egypt
}

\author{
Mohamed Negm ${ }^{*}$ and Ehab Hashish
}

\begin{abstract}
Introduction: Among transmissible spongiform encephalopathies, Creuzfeldt-Jakob disease is considered a rare neurodegenerative disorder. The clinical features include rapid progressive dementia and myoclonic jerks, which progresses to death.
\end{abstract}

Case description: We report a case of a 65 -year-old man, with progressive gait instability and impaired cognition with normal brain MRI. After 1 week, his symptoms became worse, EEG showed periodic sharp wave complexes, suggestive of Creuzfeldt-Jakob disease, and CSF was normal. One week later, he developed bradyphrenia and myoclonic fits. Brain MRI showed hyper-intensities mainly in the right frontal and occipital cortical gyri and caudate areas. After a few days, the patient developed akinetic mutism intractable fits, was admitted to the ICU, and was deceased after a few days.

Discussion and evaluation: Based on the 2010 CDC Criteria, our case was diagnosed as probable sporadic Creutzfeldt-Jakob disease (sCJD). The main findings were rapidly progressive dementia, ataxia, akinetic mutism, and myoclonus. EEG and MRI findings support the diagnosis.

Conclusions: Our case showed clinical, electrophysiological, and radiological features typical of probable sCJD—a rare, incurable, and fatal disease.

Keywords: Dementia, Creutzfeldt-Jakob disease, Prion

\section{Introduction}

Creutzfeldt-Jakob disease (CJD) is one of the human prion diseases and one of the rare progressive neurodegenerative disorders. It is a fatal disease with an annual incidence rate of $1-2$ per million worldwide. CJD is characterized by neuronal loss, gliosis, and spongiform change with accumulation of abnormal prion protein in the brain. However, it is difficult to diagnose CJD premortem because of a lack of knowledge or a low index of suspicion [1].

The forms of CJD are sporadic Creutzfeldt-Jakob disease (sCJD) (85\%-90\%), genetically transmitted (familial) (10\%), iatrogenic - which can be transmitted by contaminated surgical instruments or human tissues (dura-mater grafts, growth hormone preparations, cornea grafts, and intracranial cortical electrodes), and variant form (the

\footnotetext{
*Correspondence: Mohnegm2@yahoo.com

Faculty of Medicine, Suez Canal University, Ismailia, Egypt
}

so-called Mad Cow Disease) [1]. The mean onset age of sCJD is 65 years; most of the cases are within the age range of 60 to 80 years, both genders are nearly equally affected, and the etiology is unknown [2].

Three different stages of the disease are recognized during its clinical evolution: prodrome (lasts about 3 to 4 months), the patient presents with vague symptoms such as inattention, asthenia, weight loss, depression, sleep disorders, motor incoordination, nystagmus, and visual abnormalities; disease stage (mean duration of 4 to 5 months), it includes symptoms of cognitive compromise, progressive dementia, behavioral disorders, clinical signs of pyramidal, extrapyramidal, and cerebellar compromise; terminal stage, this is the end-stage in which the patient progresses to myoclonic jerks and coma, deteriorating to decortication and decerebration postures, dysautonomic symptoms, and seizures. The duration depends on the nursing care provided [3]. 
The diagnosis essentially depends on the clinical signs, in electroencephalographic (EEG) findings, and in the detection of the 14-3-3 protein in the spinal fluid [3-5]. However, neuropathologic features can make the definitive diagnosis [3].

EEG findings change along with the different stages of the disease; in 75 to $94 \%$ of patients, the characteristic periodic pattern can be found; however, it only can be found in the late stage of the disease (up to 12 weeks) [6].

We report a case of probable sporadic CreutzfeldtJakob disease at Suez Canal University Hospital, Egypt.

\section{Case description}

A 65-year-old hypertensive man was brought to the neurology outpatient clinic, Suez Canal University Hospital, Egypt, with about 2 weeks' history of progressive gait instability and impaired cognitive functions regarding attention and apraxia with no fever or fits. On examination, the patient was inattentive, has ataxic gait, and has increased deep tendon reflexes.

He was admitted to the hospital for investigation. Brain MRI study was done, revealing minor brain atrophy, which was considered within normal limits for patient age; there were no infarcts, masses, or extra-axial fluid collections. EEG was done as a part of the routine investigation. The EEG was markedly abnormal, with a highamplitude periodic generalized wave that occurs with a diffuse slow background. The discharges consist of sharp and triphasic waves of varying durations that repeat with a period of up to $4 \mathrm{~s}$. and they are typically anterior predominant (Fig. 1). A spinal tap was done, but his CSF had cell counts, glucose, and protein within normal limits. No metabolic abnormalities were found.

After 1 week, his symptoms became worse in the form of inability to walk and a deterioration of his cognitive functions. A new brain MRI was nonspecific; a new EEG showed the same finding as the first one. CSF was normal, but the 14-3-3 protein was requested outside the hospital as it was not available in our hospital, but unfortunately, the patient was deceased before it was fulfilled.

One week later, he developed bradyphrenia in the form of slowed thinking and processing of information and myoclonic fits. Repeated brain MRI (DWI) showed hyper-intensities mainly in the frontal lobe, cingulate gyrus, and caudate areas (more to right) along with diffuse cortical enhancement (Fig. 2). Repeated EEGs had the same typical pattern as before.

After a few days, the patient developed akinetic mutism (patients tending neither to move nor speak) and myoclonic jerks mainly with rare tonic-clonic fits which become intractable and was admitted to ICU; he went into a coma. He had urinary tract and chest infections during his stay in the ICU; finally, the patient was deceased after a few days as a result of pulmonary insufficiency.

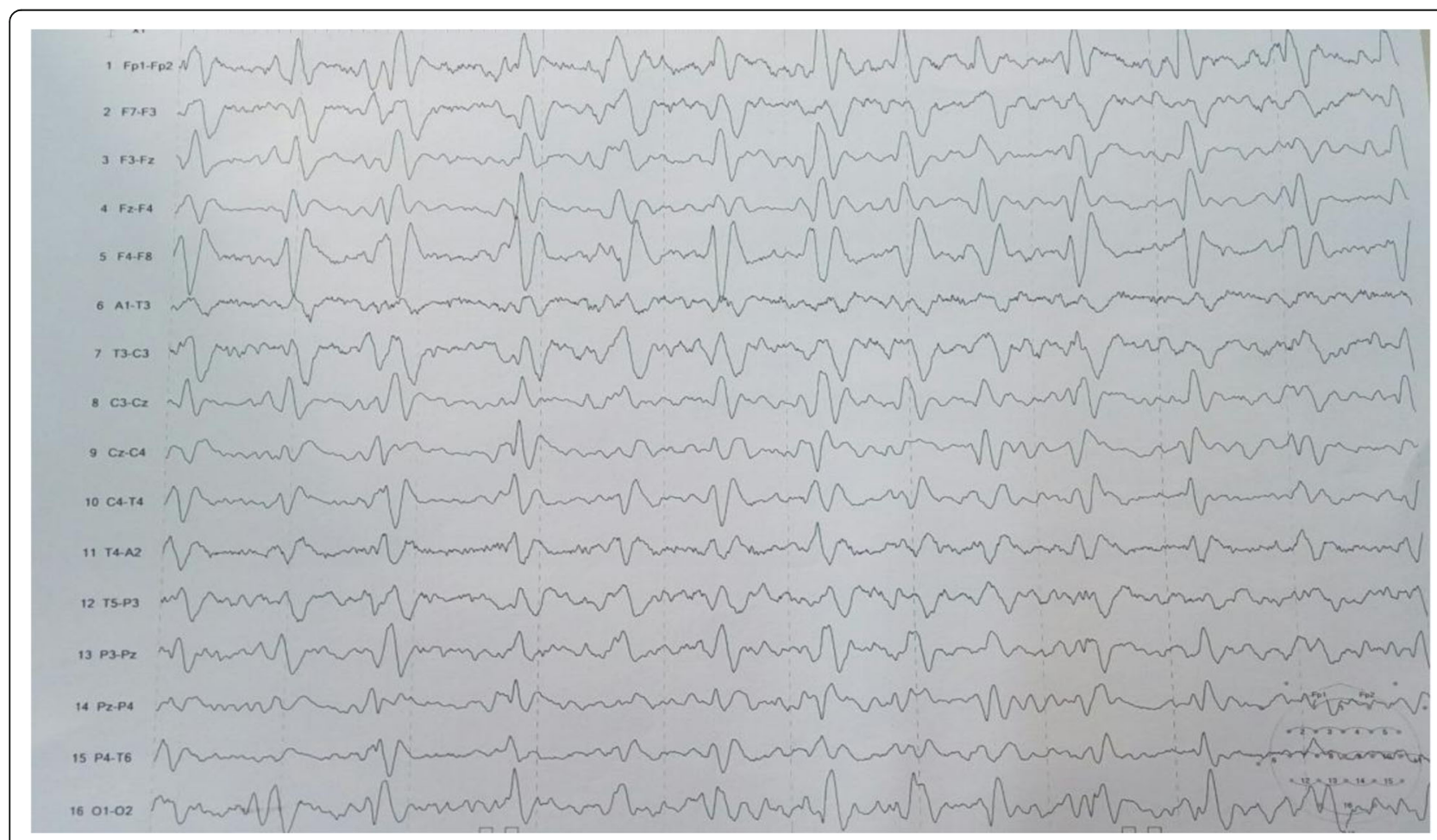

Fig. 1 EEG shows the high-amplitude periodic generalized sharp wave with diffuse slow background 

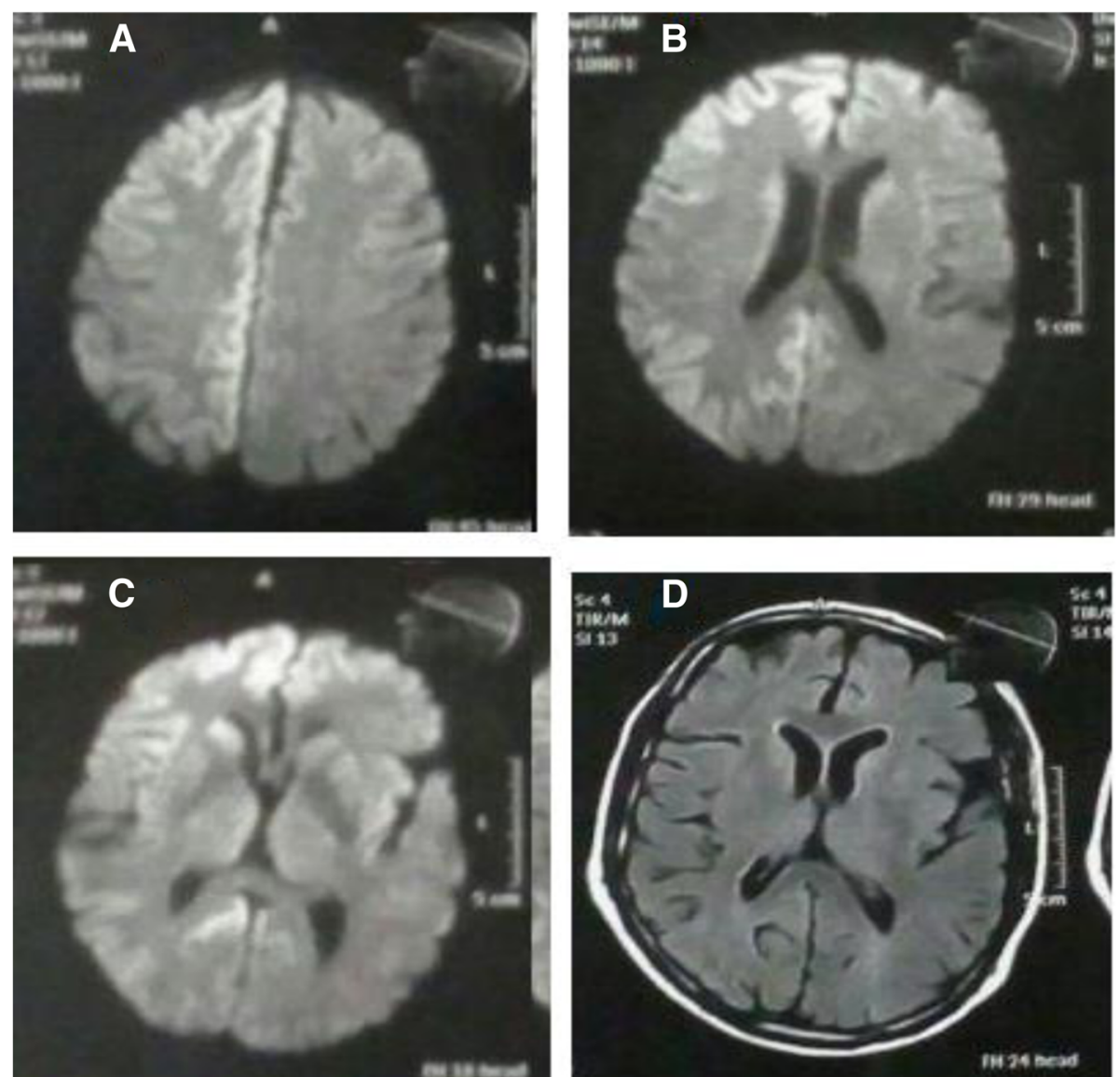

Fig. 2 Brain MRI in different sequences. MRI diffusion-weighted images showing hyperintense signal (more right) in the cingulate gyrus (a), frontal lobe (b), and caudate areas (c). T1W brain MRI with contrast image shows diffuse cortical enhancement (d)

As the patient was deceased, written informed consent was obtained from the son of the patient for publication of this case report and accompanying images.

The case report was approved by the ethics committee of the Faculty of Medicine of Suez Canal University on November 26, 2018; the registration number is 3649.

\section{Discussion and evaluation}

Sporadic Creutzfeldt-Jakob disease (sCJD) shows common findings on neurological assessment which include, but are not limited to, ataxia, pyramidal and extrapyramidal signs, rapidly progressive dementia, myoclonic fits, and visual abnormalities. Many diseases can cause these

Table 12010 CDC Criteria for sporadic CJD

\footnotetext{
Definite Detection of protease-resistant prion protein or scrapie-associated fibrils by neuropathology, immunochemical technique and/or Western blot.

Probable $\quad$ No findings indicating alternative diagnoses AND progressive dementia with at least 2 of (i)-(iv) AND at least one of (a)-(c).

Possible No findings indicating alternative diagnoses AND progressive dementia with duration of less than 2 years AND with at least 2 of (i)-(iv) AND at least one of (a)-(c).

(i) Myoclonus

(ii) Visual or cerebellar problems

(iii) Pyramidal or extrapyramidal features

(iv) Akinetic mutism

(a) Periodic sharp wave complexes on electroencephalography

(b) Positive 14-3-3 protein in the cerebrospinal fluid with a disease duration of less than 2 years

(c) High signal abnormalities in the caudate nucleus and/or putamen on diffusion-weighted imaging (DWI) or fluid-attenuated inversion recovery (FLAIR) MRI
} 
symptoms, so it is non-specific [1]. Diagnosis of sCJD can be classified as definite, probable, and possible (Table 1) [1].

Based on these criteria, our case was diagnosed with probable sCJD. The main findings were rapidly progressive dementia, ataxia, akinetic mutism, and myoclonus. EEG findings and MRI findings (Figs. 1 and 2) support the diagnosis. Myoclonic fits occur after admission and akinetic mutism occurs late, and this comes in accordance with Rabinovici et al. [7]. Protein 14-3-3 was not fulfilled; however, this is not a specific finding.

Typical EEG in CJD is composed of periodic generalized biphasic or triphasic complexes (lasting for 100 to $300 \mathrm{~ms}$, with a mean amplitude of $300 \mu \mathrm{V}$ ) and an interval among repetitions of 0.5 to $4 \mathrm{~s}[6,8]$. Our EEG finding in this case comes in accordance with these criteria which support the diagnosis.

Steinhoff et al. [9] in 2004 reported that in 150 patients who underwent autopsy, the EEG has a sensitivity of $64 \%$, specificity of $91 \%$, a positive predictive value of $95 \%$, and a negative predictive value of $49 \%$. Also, Markand [6] reported that typical EEG pattern can be demonstrated in 75 to $94 \%$ of patients. On the other hand, Zerr and colleagues [10] found a sensitivity of $66 \%$ and a specificity of $74 \%$ and reported that finding of the 14-3-3 protein in the CSF predicts the highest sensitivity and specificity ( $94 \%$ and $84 \%$, respectively).

\section{Conclusions}

Our case showed clinical, electrophysiological, and radiological features probable of $\mathrm{SCJD}-\mathrm{a}$ rare, incurable, and fatal disease. Early and accurate diagnosis is important because some of the differential diagnoses such as viral or bacterial encephalitis are treatable. Early diagnosis also allows patients and their families to understand the expected disease course and possibly arrange for palliative care consultation.

\section{Abbreviations}

CDC: Centers for Disease Control; CJD: Creutzfeldt-Jakob disease; CSF: Cerebro spinal fluid; DWI: Diffusion-weighted images; EEG: Electroencephalographic; ICU: Intensive care unit; MRI: Magnetic resonance imaging; sCJD: Sporadic Creutzfeldt-Jakob disease

\section{Acknowledgements}

Not applicable

\section{Authors' contributions}

MN contributed to the idea, writing of the case report, and final revision of the manuscript. EH contributed to the idea, the collection of data, and final revision of the manuscript. All authors read and approved the final manuscript.

\section{Funding}

Not applicable

Availability of data and materials

Data are available from the authors upon reasonable request.
Ethics approval and consent to participate

The case report was approved by the ethics committee of the Faculty of Medicine of Suez Canal University on November 26, 2018; the registration number is 3649 .

As the patient was deceased, written informed consent was obtained from the son of the patient for publication of this case report and its accompanying images.

\section{Consent for publication}

Consent was obtained from the son of the patient for publication of this case report and its accompanying images.

\section{Competing interests}

The authors declare that they have no competing interests.

Received: 26 November 2018 Accepted: 20 May 2019

Published online: 04 June 2019

\section{References}

1. Department of Health and Human Services, Centers for Disease Control and Prevention, CJD (Creutzfeldt-Jakob Disease, Classic), author 2010. [June 1st 2012]. http://www.cdc.gov/prions/cjd/index.html.

2. Ladogana A, Puopolo M, Croes EA, et al. Mortality from Creutzfeldt-Jakob disease and related disorders in Europe, Australia, and Canada. Neurology. 2005;64(9):1586-91.

3. Yasuda N, Scaff M. Doença de Creutzfeldt-Jakob e encefalopatia espongiforme bovina. In: Encefalopatia espongiforme transmissível: caderno técnico. $1^{\text {a }}$ ed. Brasília; 2004.

4. Silva AM, et al. Estudo Retrospectivo da Doença de Creutzfeldt-Jakob diagnosticada no Norte de Portugal entre 1993-2002. Arq Neuropsquiatr. 2003:61(4):950-6.

5. Arruda WO, et al. Doença de Creutzfeldt-Jakob Forma Heidenhain - Relato de caso com achados de ressonância magnética e DWI. Arq Neuropsiquiatr. 2004;62(2-A):347-52

6. Markand ON. Daly DD, Pedley TA, editors. editorsOrganic brain syndromes and dementias. In: current practice of clinical electroencephalography. New York: Rave press. p. 413-5.

7. Rabinovici GD, Wang PN, Levin J, et al. First symptom in sporadic Creutzfeldt-Jakob disease. Neurology. 2006;66(2):286-7.

8. Ortega-Albás JJ, Serrano-García AL. Neurofisiologia en la enfermedad de Creutzfeldt-Jakob. Rev Neurol. 2003;36(4):376-80.

9. Steinhoff BJ, et al. Diagnostic value of periodic complexes in CreutzfeldtJakob disease. Ann Neurol. 2004;56(5):702-8.

10. Zerr I, Pocchiari M, Collins S, et al. Analysis of EEG and CSF 14-3-3 proteins as aids to the diagnosis of Creutzfeldt-Jakob disease. Neurology. 2000;55(6): 811.

\section{Publisher's Note}

Springer Nature remains neutral with regard to jurisdictional claims in published maps and institutional affiliations.

\section{Submit your manuscript to a SpringerOpen ${ }^{\circ}$ journal and benefit from:}

- Convenient online submission

- Rigorous peer review

- Open access: articles freely available online

High visibility within the field

- Retaining the copyright to your article

Submit your next manuscript at $>$ springeropen.com 